\title{
Anatomo-topographic and histo-cytological study of dromedary's spleen in Algeria
}

\author{
M.A. Fares ${ }^{1}\left[\right.$, T. Khenenou' ${ }^{1}$, D.E. Rahmoun²(1) \\ 'Laboratory of Sciences and Technics of the Livings, Institute of Agriculture and Veterinary Sciences, Taoura, \\ University of Souk Ahras, Algeria \\ ¿2aboratory of Animal Production, Biotechnologies and Health (PABIOS), Institute of Agriculture and Veterinary Sciences \\ Taoura, University of Souk Ahras, Algeria
}

[Received: 13 August 2021; Accepted: 5 November 2021; Early publication date: 17 January 2022]

Background: Twenty-five spleens of adult, healthy dromedary of the local breed from the region of El Oued, Algeria, were collected at the slaughterhouse in order to carry out research to determine the macroscopic and microscopic structure of spleen in this species, macroscopic study revealed that the spleen has a rectangular shape with a triangular section, rounded edges, a little bit striated, its surface is smooth in which the aspect of the capsule and the parietal surface is shiny and smooth, the morphometric study was carried out after classifying the sampled spleen in five groups according to the animal's body weight which increases with age.

Materials and methods: Our study revealed that the groups show a different value of mass which declines towards a drop of the index, also the indexes of length and width are following a decreasing order.

Results: The histological study revealed that the zone occupied by stroma did not exceed $26.81 \%$ of the total components of the capsule which is composed essentially of connective tissue and an inner layer of smooth muscle cells. Vascular and avascular trabeculae extend from the capsule. The immunohistochemistry study made it possible to visualise $T$ lymphocytes of the splenic parenchyma using monoclonal antibodies where a statistical study was carried out to determine the composition of the various compartments of this organ. The localisation of immunocompetent cells in the splenic parenchyma has been elucidated with antibodies specific for $T$ lymphocytes.

Conclusions: The red pulp occupied a maximum area of the spleen with an average of $68.1 \%$ composed of sinusoids venous, the cords extend between the sinuses and the interlobular zone contain many cells: macrophages, plasma cells, red blood cells, white blood cells and platelets. (Folia Morphol 2023; 82, 1: 137-146)

Key words: dromedary, lymphocytes, spleen, peri-arteriolar lymphoid sheath, red pulp, white pulp

\section{INTRODUCTION}

The spleen is the largest secondary lymphoid organ in mammals and also the primary site for prolif- eration and differentiation of immune cells and has been described as a centre of blood filtration [5]. The splenic parenchyma has a crucial role in immune

Address for correspondence: Dr. M.A. Fares, PhD Student, Veterinary Anatomy, Laboratory of Sciences and Techniques of Living, Institute of Agriculture and Veterinary Sciences, Taoura, University of Mohamed Cherif Messaadia Souk Ahras, B.P. 1553, Route de Annaba, 41000, Algeria, tel: +213696490031, e-mail: faresamin1995i@gmail.com

This article is available in open access under Creative Common Attribution-Non-Commercial-No Derivatives 4.0 International (CC BY-NC-ND 4.0) license, allowing to download articles and share them with others as long as they credit the authors and the publisher, but without permission to change them in any way or use them commercially. 
responses such as exposure to antigens transmitted by blood according to studies by Kannan et al. [14].

Research by Mahadevan [16] demonstrated that the spleen is an organ deep red to blue-black located in the left cranial abdomen, it is adjacent to the greater curvature of the stomach and the omentum is an elongated organ with an approximately triangular section. According to the results of studies by Masternak and Bartke [17] and Mahadevan [16], the size of the spleen varies according to the species and the degree of distension; nonetheless, the mass of the spleen may be important in its assessment. The splenic weight to body weight ratio remains fairly constant regardless of age in most mammals and is generally around $0.2 \%$.

Researchers such as Paraskevas et al. [25] and $\mathrm{Xu}$ et al. [33], have demonstrated that the spleen is composed of two functionally and morphologically distinct compartments, the red pulp and the white pulp, the red pulp is a blood filter that removes foreign bodies, erythrocytes, and damaged material, it is a site of haematopoiesis, especially in fetuses and newborn animals. Almenar et al. [1] also described that the spleen is the largest secondary lymphoid organ, containing about a quarter of the body's lymphocytes and it is the one that initiates immune responses to antigens carried by the blood, this function is charged to the white pulp which surrounds the central arterioles, the white pulp is composed of three sub-compartments, the peri-arteriolar lymphoid sheath (PALS), the follicles and the marginal area, this has been shown by Nolte et al. [22]. Histo-cytometric research by Kage et al. [13] and Almenar et al. [1] shows that the spleen is surrounded by a capsule composed of dense fibrous tissue, elastic fibres, and smooth muscle, the outermost layer of the capsule. Splenic is composed of mesothelial cells, the irregularly spaced trabeculae of smooth muscle and elastic fibre tissues that emerge from the capsule to the splenic parenchyma $[28,30]$. On the other hand, Rahmoun et al. [29] showed that these trabeculae also contain blood vessels, lymphatics, and nerves.

Looking at the studies of Mollejo et al. [21] who demonstrated that the red pulp is composed of a three-dimensional mesh of the splenic cords and venous sinuses, the spleen cords are composed of the reticular fibres, reticular cells, and macrophages. The white pulp is subdivided into PALS, follicles, and marginal zone, it is composed of lymphocytes, macrophages, dendritic cells, plasma cells, arterioles, and capillaries in a reticular framework similar to that found in the red pulp, the arterioles entering the latter is surrounded by PALS which are composed of lymphocytes and layers of reticular fibres and flattened reticular cells concentrated according to Dijkstra et al. [3]. The internal PALS cells are largely CD4 T lymphocytes, although lower numbers of CD8 T lymphocytes may also be present, inter-digitised dendritic cells and migrating B cells according to Johnson [12]. The outer PALS is populated with small and medium-sized lymphocytes (B and T cells), macrophages, and plasma cells according to studies by Matsuno et al. [18] and Johnson [12].

The marginal zone is a unique region of the spleen located at the interface of the red pulp with PALS and the follicles considered by many authors to be a separate compartment rather than part of the white pulp, it is designed to filter the systemic circulation to eliminate antigens and pathogens according to Kuper et al. [15] and Bar-Ephraïm and Mebius [2]. Marginal zone macrophages are a unique subset of macrophages at the inner margin of the marginal zone adjacent to PALS and follicles according to Dijkstra et al. [3] and Nolte et al. [22].

The endothelial cells coating the sinuses according to Bar-Ephraïm and Mebius [2]. At the level of the marginal sinus, according to the research of Kage et al. [13] and McGaha and Karlsson [19] have shown that there is a presence of a thick external crown of the marginal zone, composed of reticular fibroblasts, marginal macrophages, medium-sized dendritic cells, and marginal zone B cells, which merge into the red pulp. Macrophages from marginal areas constitute another population of splenic macrophages which stain with the monoclonal antibody ERTR-9 according to Johnson [12]. Marginal zone macrophages are important in the elimination of microorganisms and viruses; they express several pattern recognition receptors such as toll receptors and macrophage receptors with collagen structure, which play a role important in the absorption of various bacteria. Marginal zone $B$ cells are a unique subset of non-circulating $B$ cells having an $\operatorname{lgM} / \mathrm{lgD}$ phenotype as opposed to follicular $B$ cells which are $\operatorname{lgM} / \lg D$ according to the results of studies by Johnson [12] and Middleton et al. [20].

\section{MATERIALS AND METHODS}

The studies were carried out in the Laboratory of Science and Technique of Living, Institute of Agronomic and Veterinarian Sciences, University of Mohamed Cherif Messaâdia, Souk Ahras, Algeria. The 
research material was clinically healthy, sexually mature dromedary spleens (Camelus dromedarius) from the El-Oued region of southern Algeria. The animals have not been vaccinated throughout their lives. Material selection took place at the town's communal slaughterhouse after the animals were slaughtered by bleeding. Before slaughter, the animals underwent a mandatory veterinary examination, weighing, and age determination, the animals were classified according to bodyweight into five groups, The first group composed of animals that had a bodyweight compromised between $328 \mathrm{~kg}$ and $353 \mathrm{~kg}$, whereas the animals classified in the second group had a bodyweight compromised between $353 \mathrm{~kg}$ and $378 \mathrm{~kg}$, while the animals of the third group had a bodyweight compromised between $378 \mathrm{~kg}$ and $393 \mathrm{~kg}$, and the fourth group composed of animals that had a bodyweight between $393 \mathrm{~kg}$ and $418 \mathrm{~kg}$, and finally, the animals of the fifth group had a bodyweight compromised between $418 \mathrm{~kg}$ and $433 \mathrm{~kg}$.

When selecting the material, the topographic characteristics of the spleens were determined. Absolute organ mass was determined using a Techniprot-WTW scale accurate to $0.002 \mathrm{mg}$. The relative weight of the spleens concerning the bodyweight of the dromedary was also calculated. The linear measurements (length, width) of each spleen were determined using a centimetre ruler.

Microscopic investigations were carried out after fixing the samples in a $5 \%$ solution of neutral formalin for 10 days, then in $10 \%$ for $12-16$ days, followed by storage of the material in this solution for the entire period of the morphological research. For the preparation of histological sections, the samples were cut perpendicularly, selecting five segments from each group. The fragments were incorporated into paraffin after washing with running water; the dehydration was carried out using ethanol with increasing concentration. The casting has been completed. Histological sections 7-10 $\mu \mathrm{m}$ thick were stained with haematoxylin and eosin, according to Van Gieson, Azure II-eosin. The characteristics of the cytoarchitectonics and the lymphoid structure were determined using an MBS-10 biological stereoscopic microscope $(8 \times$ eyepieces, $4 \times$ objectives, $7 \times)$ and a B-382PLi-ALC light microscope $(10 \times$ eyepieces, $10 \times$ objectives, $40 \times, 100 \times$ ). A quantitative (morphometric) analysis of structural components was performed by the "spot count" method using eye test systems (inserts) (3 measurements on 5 preparations obtained from each spleen).
The relative area of connective tissue was determined (trabeculae, capsules, and thickening of the hilum, relative area of lymphoid parenchyma as a whole, and in distinct functional areas [capsule, trabecula, red pulp, peri-arterioral lymphoid sheath, total white pulp, inactive and active follicle]). The cytoarchitectonics of the individual functional areas of the spleens of the different areas of the splenic parenchyma was determined on thin sections of paraffin stained with Azure II-eosin. The cell count is the relative amount of the lymphoid line, was performed using an Olympus IX71 Inverted Microscope cytometric microscope with an increase of 10-100 under emersion. Based on the data obtained, the average percentage of each type of cellular element was determined.

An immunohistochemical study was performed to determine the localisation of $\mathrm{T}$ and $\mathrm{B}$ lymphocyte populations in the functional areas of the lymphoid parenchyma of the spleens. For the study, the segments were fixed in a $10 \%$ neutral formalin solution, followed by standard routing through alcohols of increasing concentration, after which they were poured into paraffin, and thin sections of 4 to $5 \mu \mathrm{m}$ thick were made. Immunohistochemical studies were performed by the direct Koons method according to the method of Matsuno et al. [18] Cells immune systems were differentiated using monoclonal antibodies. Antibodies to the CD3 antigen ( $T$ cells were used). Diaminobenzidine (DAB) was used as a chromogen. Sections were further stained with haematoxylin, with additional dehydration, clarification in xylene, and incorporation into polystyrene. The statistical analysis of the results was carried out using Statistica 10.0 (StatSoft Inc., USA), and the differences between samples were determined using ANOVA and were considered significant at $\leq 0.05, \leq 0.01, \leq 0.001$. The quantitative study for the tissue compartments was carried out using the point $\mathrm{S}$ system.

\section{RESULTS}

After dissection of the animals, it was found that the spleen presents a semi-lunar shape, of firm consistency, of red-brown colour surrounded by a layer of thick connective tissue, it was found that this organ is composed of two compartments which are the body and extremities, this organ is located under the left hypochondrium behind the stomach cavities above the dorsal bag of the rumen to the posterior part of the kidney. Regarding the spleen mass, it was 
found that the minimal absolute mass was $236 \mathrm{~g}$ in the first group, whereas the maximal mass was $336 \mathrm{~g}$ observed in the fifth group. In the other groups, the mass followed an ascending order from the second to the fourth, in which the observed values were $267 \mathrm{~g}, 280 \mathrm{~g}$ and $297 \mathrm{~g}$, respectively (Fig. 1).

The length of the spleens as a value a variation between groups and followed an ascending order same the mass, in which the minimal length value was $40.10 \mathrm{~cm}$ observed in the first group, while the maximal length was $51.30 \mathrm{~cm}$ observed in the fifth group. The width also showed a variation following an ascending order from the second to the fourth group in which the values were $47.3 \mathrm{~cm}, 49.9 \mathrm{~cm}$ and $50.6 \mathrm{~cm}$, respectively, the minimal value of width was $17.60 \mathrm{~cm}$ found in the first group, whereas the maximal width was 26.40 observed in the fifth group, the other values of the third, fourth and fourth group were respectively $44.1 \mathrm{~cm}, 44.5 \mathrm{~cm}$ and $45.8 \mathrm{~cm}$ (Figs. 1, 2).

The outer layer mainly consisted of connective tissue including collagen, rubber bands and fibroblasts and smooth muscle cells (SMC). The inner layer was made up mostly of SMC that appear parallel along the longitudinal cut. Trabeculae extend from the capsule and branch out, so that it divides the area into several parts, are distinguished by the presence of white fibres and smooth muscle fibres. At high magnification, it was observed that the space between the capsule and the parenchyma contained red blood cells, so the surface of the white pulp was large, irregular in shape, the PALS had a clear surface with a branching central artery in several branches, the lymphatic follicles and the marginal zone were very clear.

A large marginal area surrounded the white pulp and it was contained in sheathed arteries and SMC. Also, it was observed that the marginal sinus of the marginal zone infiltrates in the marginal zone in the direction of the red pulp supplying the blood directly in the adjacent venous sinuses whose ends which appear open with the marginal zone and penetrate into the reticular mesh of the red pulp and bypass the reticular mesh of the red pulp. It was found that blood from the red pulp collects in the venous sinuses which enter the trabeculae and merge into the trabecular veins, the trabecular veins then converge at the hilum to form the splenic vein which drains to the exterior of the organ (Fig. 3).

Regarding the red pulp, it was found to be composed of a mesh of splenic cords and venous sinuses. At high magnification, the splenic cords are composed

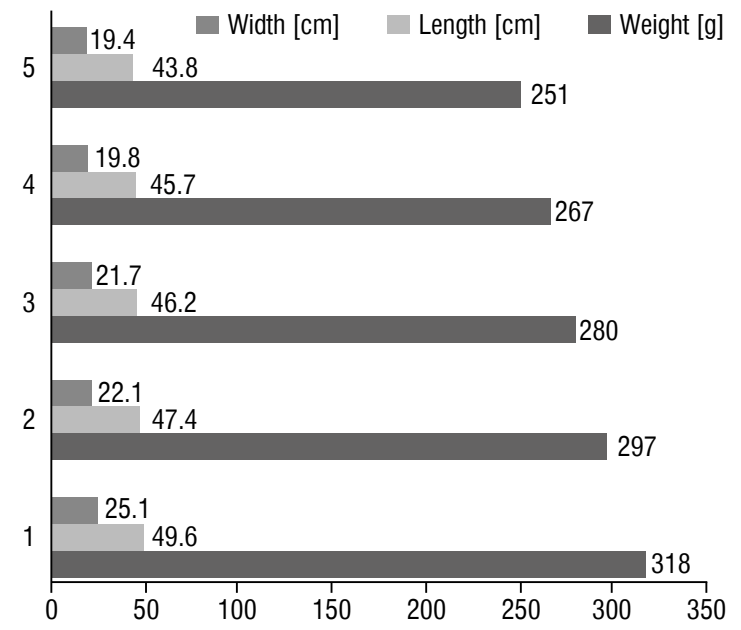

Figure 1. Index of mass, length and width of dromedary spleens according to the groups.

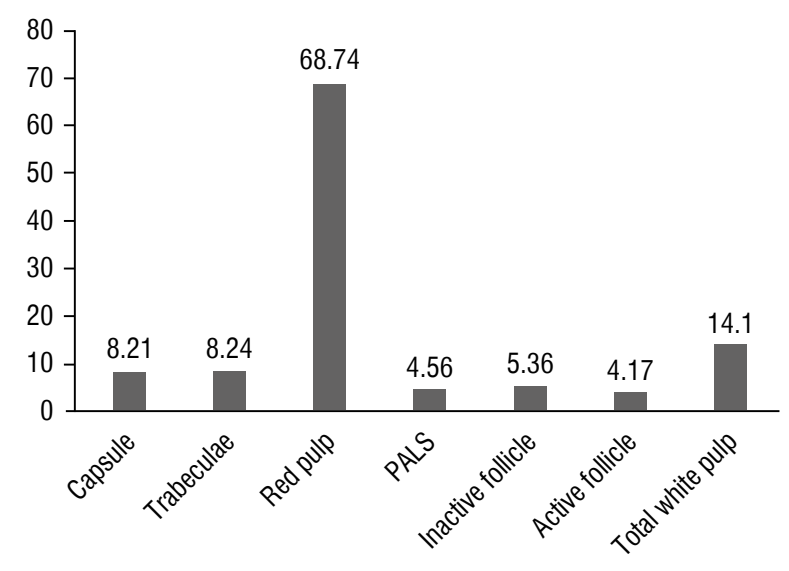

Figure 2. Index of tissue composition of dromedary spleen (\%); PALS - peri-arterioral lymphoid sheath.

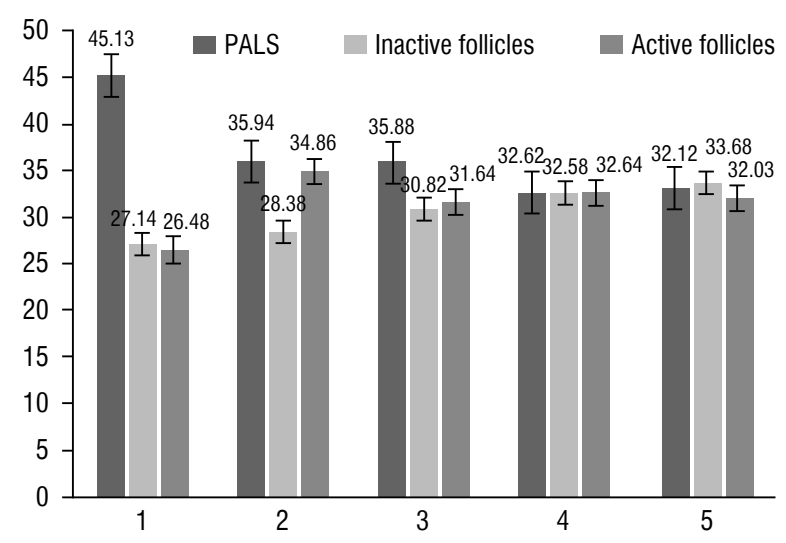

Figure 3. Index of parenchyma composition of dromedary spleen (\%); PALS - peri-arterioral lymphoid sheath.

of reticular fibres, reticular cells and macrophages. Again, under the microscope it was found that the 


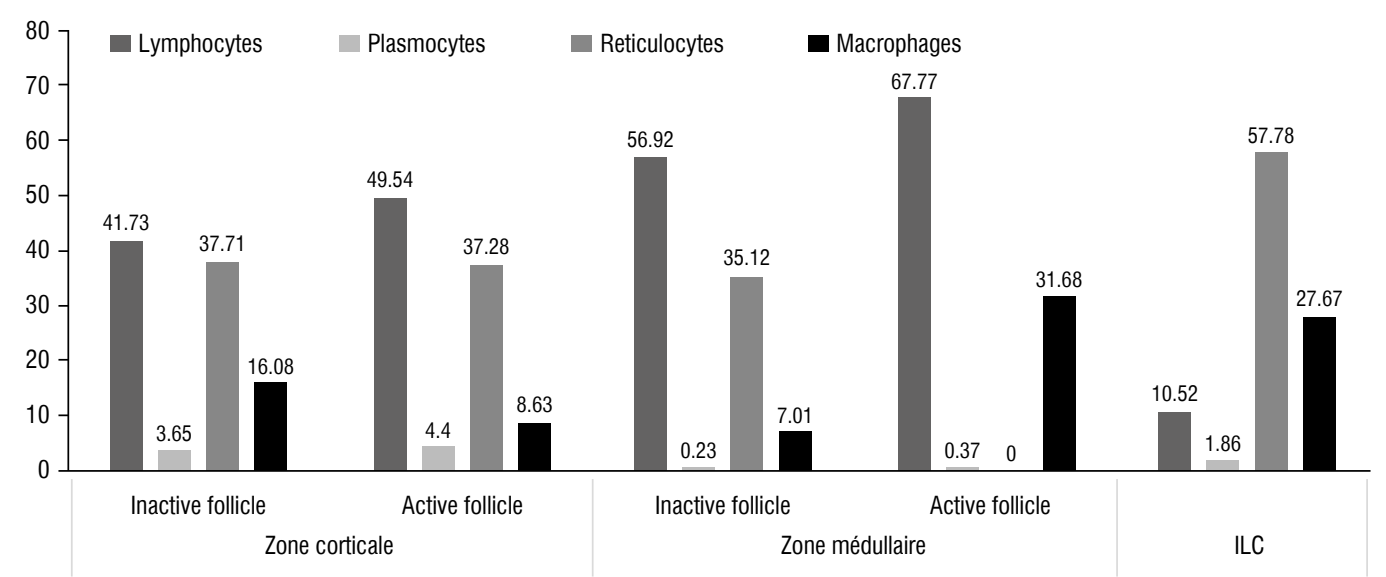

Figure 4. Index of the cellular composition of the dromedary spleen (\%); ILC — intralobular connective tissue.

venous sinuses can occupy the entire surface of the red pulp including, they are lined with epithelial tissue and rest on a basement membrane, the periciliary arteries and arteriolar capillaries are also located in the pulp red (Fig. 3).

The statistical study revealed that the stroma which is constituted by capsule and trabecula, the maximal area occupied by the capsule was $13.18 \pm$ $\pm 1.93 \%$ observed in the fifth group, with a minimal value of $5.27 \pm 2.53 \%$ observed in the second group, while the trabecula occupied an area of $13.54 \pm$ $\pm 1.62 \%$ as maximal value observed in the fourth group, while the minimum value was about $4.36 \pm$ $\pm 1.53 \%$ observed in the second group, whereas the red pulp occupied a zone with a minimum value of $52.36 \pm 1.72 \%$ found in the fourth group, and the maximal value was about $68.09 \pm 0.77 \%$ found in the second group (Fig. 4).

The parenchyma and its components were considered as a lymphoid organ integrated into the spleen, for the PALS the minimal value was $32.12 \pm$ $\pm 1.38 \%$ observed in the fifth group, whereas the maximal value was $45.13 \pm 1.47 \%$ found in the first group, while the zone occupied by the inactive follicles revealed that the minimal value was $27.14 \pm$ $\pm 1.58 \%$ observed in the first group, whereas the maximal value was $33.68 \pm 1.17 \%$ found in the fifth group. While the area occupied by the active follicles showed a minimum value of $26.48 \pm 1.71 \%$ observed in the first group, while the maximal value was $32.64 \pm 1.27 \%$ observed in the fourth group (Fig. 5).

Under the high magnification microscope, we could see that the red pulp is formed by blood sinuses

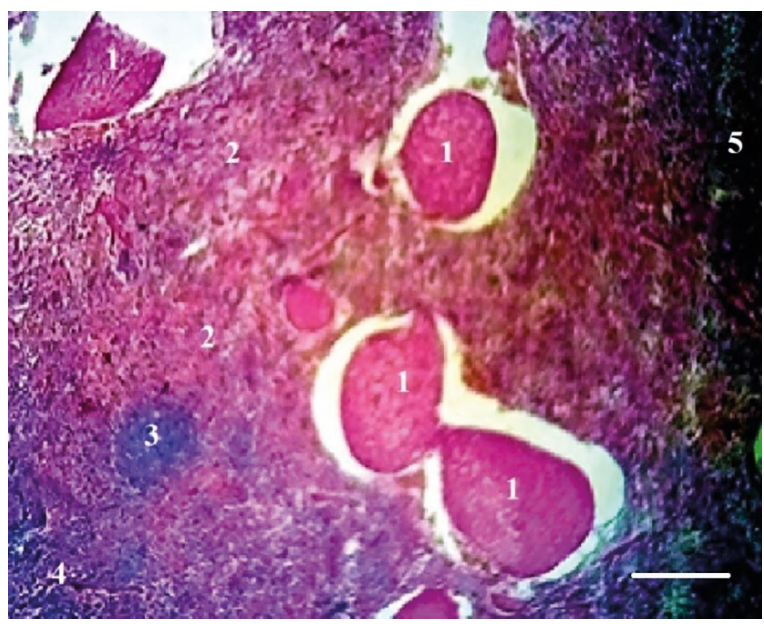

Figure 5. Histological section of the spleen of the dromedary, haematoxylin eosin staining; 1 - red pulp; 2 - white pulp; 3 - follicle; 4 - cortical zone; 5 - medullary zone. Bar $=100 \mu \mathrm{m}$.

and Billroth cell cords; the sinus wall is very thick. The cords extend between the sinuses and contain macrophages, plasma cells, erythrocytes, lymphocytes and also platelets. Also, we could see that the white pulp consists of clusters of lymphoid tissue, including Hassal corpuscles, the latter formed a PALS around the central arteries (Fig. 6).

In these areas there are active and inactive lymphoid follicles, which are rich in lymphocytes and plasma cells. A marginal area was found at the junction of the red pulp and the white pulp, which contains lymphoid cells and macrophages. It is separated from the white pulp by the marginal sinus formed by a terminal branch of the central artery. It was also possible to detect the reticular cells which formed a surface in the integrity of the organ's framework (Figs. $6,7,8$ ). 


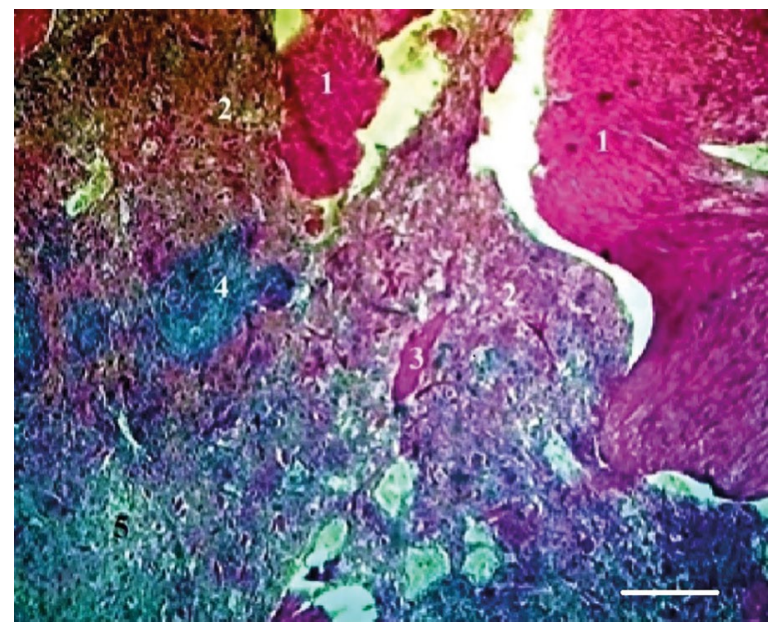

Figure 6. Histological section of the dromedary spleen, haematoxylin eosin staining; 1 - red pulp; 2 - white pulp; 3 - pulp sinus; 4 - medullary zone. Bar $=100 \mu \mathrm{m}$.

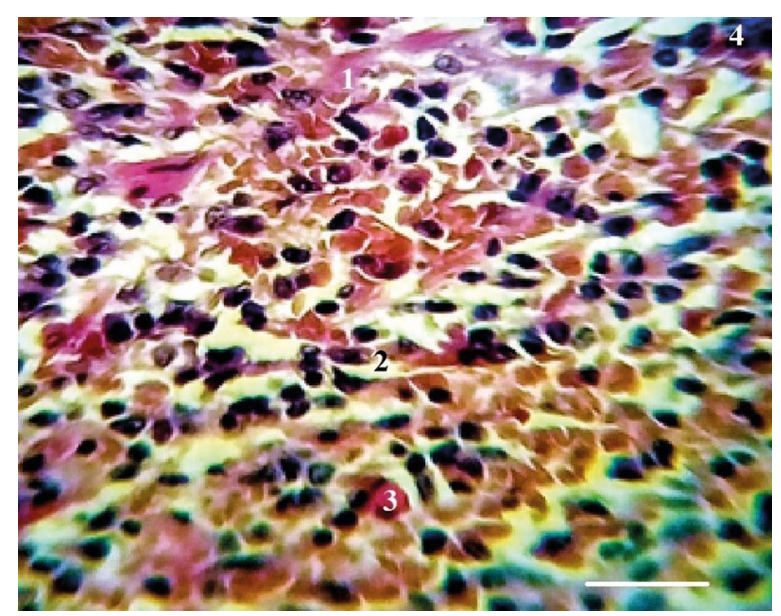

Figure 7. Histological section of the dromedary spleen, Azur II-eosin staining; 1 - reticulocyte; 2 - lymphocyte; 3 - macrophage; $4-$ large lymphocyte. Bar $=20 \mu \mathrm{m}$.

The use of the immunological translation of lymphocytes at the level of the splenic parenchyma has been identified by the use of anti-CD3 antibodies, their fixations of which are planned at the precisely follicular medullary level, lymphocyte frames clearly visible at the level of the chin of the follicles as well as in the peri-arterial space of the splenic parenchyma of variable density according to the reaction of the lymphocytes (Fig. 9).

On the other hand, we were able to visualise the B lymphocytes with the use of anti-CD3, whose binding appears clearly at the inter follicular level whose mass appears after lymphocyte reaction in general the spleen of the dromedary is in the immunogenic system very active (Fig. 10).

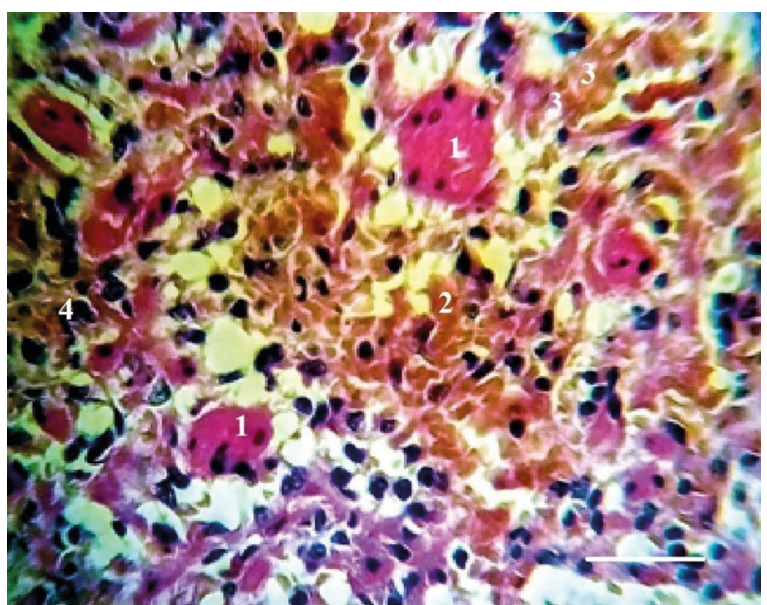

Figure 8. Histological section of the dromedary spleen, Azur II-eosin staining; 1 - red pulp concentration; 2 - reticulocyte; 3 macrophage; 4 - lymphocyte. Bar $=20 \mu \mathrm{m}$.

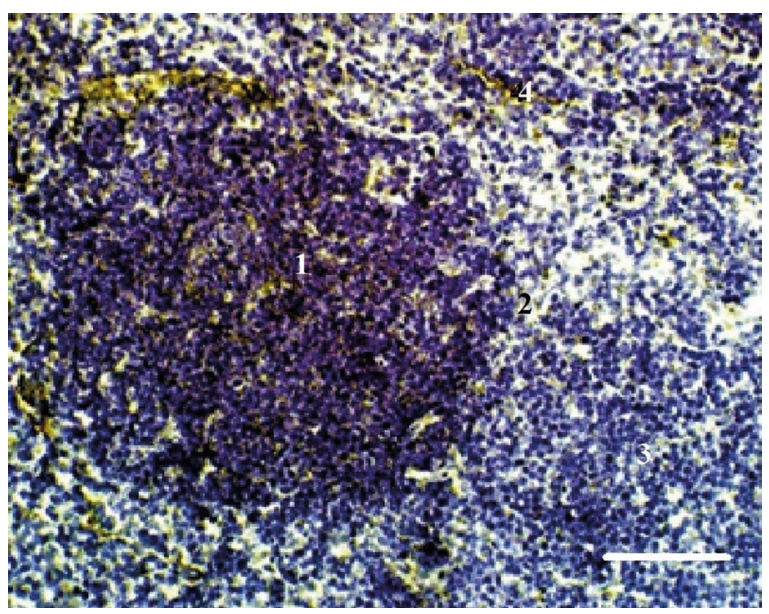

Figure 9. Histological section of the dromedary spleen, immunohistochemical reaction against CD3 T lymphocyte; 1 - follicular centre; 2 - follicular periphery; 3 - cortical zone; 4 - lymphocytic reaction. Bar $=20 \mu \mathrm{m}$.

The statistic study of cellular components revealed that the cortical zone components showed different but close values, the lymphocytes occupied a zone of $41.73 \pm 1.48 \%$ in the inactive follicles, in contrast, it occupied a zone of $49.54 \pm 1.62 \%$ in the active follicles, the reticulocytes occupied a zone of $13.65 \pm$ $\pm 1.29 \%$ in the inactive follicles, whereas they occupied an area of $9.4 \pm 1.29 \%$ in the active follicles, plasmocytes occupied $25.71 \pm 1.29 \%$ of the inactive, while they occupied $22.28 \pm 1.73 \%$ in the active follicles, macrophages occupied a zone of $18.08 \pm$ $\pm 1.67 \%$ in the inactive follicles, whereas they occupied an area of $18.63 \pm 0.74 \%$ in the active follicles. The medullar zone showed a general distribution of 


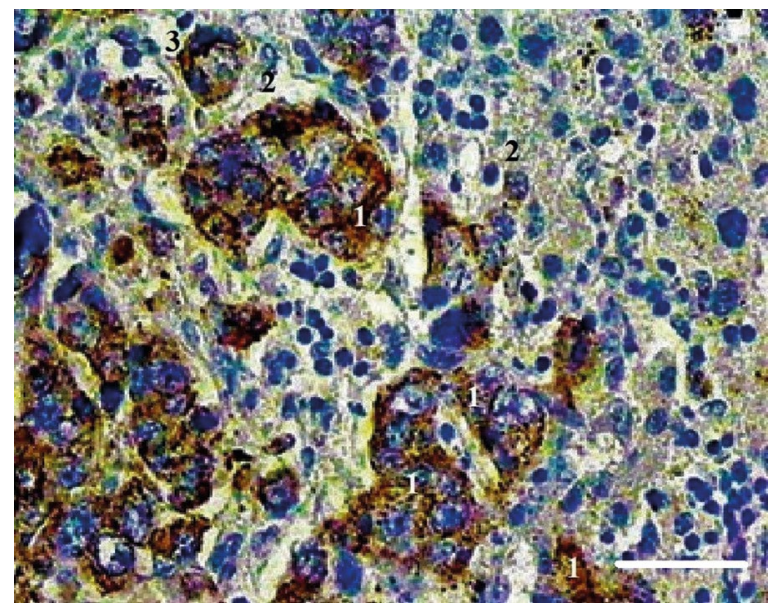

Figure 10. Histological section of the dromedary spleen, immunohistochemical reaction against CD3 T lymphocyte; 1 - lymphocyte; 2 - macrophage; 3 - lymphocyte in reaction. Bar $=20 \mu \mathrm{m}$.

values close to the cortical zone, the lymphocytes occupied a zone of $51.92 \pm 1.98 \%$ in the inactive follicles, whereas they occupied a zone of $50.77 \pm 1.42 \%$ in the active follicles, the reticulocytes occupied an area of $6.23 \pm 1.21 \%$ in the inactive follicles, while they occupied an area $4.37 \pm 0.83 \%$ in the actives ones, plasmocytes occupied $24.12 \pm 1.78 \%$ of the inactive follicles, whereas they occupied $25.58 \pm 2.07 \%$ in the active follicles, macrophages occupied a zone of $17.01 \pm 1.71 \%$ in the inactive follicles, whereas they occupied a zone of $18.68 \pm 2.13 \%$ in the active ones. The intralobular connective tissue showed the same organization of values as the cortical and the medullar zone, the lymphocytes occupied an area of $45.52 \pm$ $\pm 1.55 \%$, reticulocytes occupied $5.34 \pm 2.73 \%$, while plasmocytes and macrophages occupied respectively $22.12 \pm 1.69 \%$ and $26.67 \pm 3.18 \%$ (Fig. 3).

\section{DISCUSSION}

In this study, the spleen of the dromedary was compared with those of other animals. The spleen is an organ of the circulatory and immune systems. It monitors the condition of blood cells and can be used to accumulate blood. In addition, the spleen is involved in lymphopoiesis and can capture and accumulate certain metabolic products. According to researchers $[16,28,30]$, the appearance of the spleen of a dog and a cat is similar, it is flat and elongated, with a narrow dorsal end and a wider ventral end. Its parietal surface is smooth, on the visceral surface there are elongated spleen doors, in the hilum area the spleen is relatively loosely connected with a large omentum. According to Jaji et al. [11], predicts that the spleen is always adjacent to the left abdominal wall, its position largely depends on the fullness of the stomach.

However, the spleen can accumulate up to $16 \%$ of all a dog's blood, affecting the displacement of the ventral end to the right half of the abdomen. With an empty stomach, a dog's spleen is completely located in the hypochondrium, while in a cat, in this case, its ventral end is always outside the hypochondrium. With a moderately full stomach and in a dog, the ventral end of the spleen protrudes caudally beyond the edge of the costal arch. When the stomach is full, the spleen is located in the iliac region and sometimes reaches the entrance to the pelvis $[4,7]$.

Prasad [26] noted that the dorsal end of the spleen is less mobile compared to the ventral one, because in this part of the spleen the gastro-splenic ligament is rather firmly attached to the greater curvature of the stomach. Our results concerning the spleen of the dromedary are almost the same as demonstrated by the researchers; it presents a semi-lunar shape, of firm consistency, of red-brown colour surrounded by a layer of thick connective tissue. It was found that the organ is divided into two compartments: the main body and two extensions at each opposite ends. This organ is located under the left hypochondrium behind the stomach cavities above the dorsal bag of the rumen up to the posterior part of the kidney.

In our research of the mass of the spleen of the dromedary, the maximum value of the absolute mass varied between $318 \mathrm{~g}$ and $251 \mathrm{~g}$, with a relative mass between $0.07001 \%$ and $0.07470 \%$. The maximum length of the spleen was $49.60 \mathrm{~cm}$, while the minimum length was $43.80 \mathrm{~cm}$; for the width, the maximum value was $25.10 \mathrm{~cm}$, and the minimum value of the width was $19.40 \mathrm{~cm}$.

Regarding the tissue components of the spleen, it was found that the area limited by the stroma is $9.19 \%$, for the first spleen, whose capsule occupies an area of $5.44 \%$, while the trabecula occupies an area of $3.75 \%$, while the area occupied by red pulp was $76.54 \%$, and that occupied by the parenchyma was $13.38 \%$, of which the area occupied by the PALS was $7.54 \%$, and that occupied by inactive follicles was $3.67 \%$, while the area occupied by active follicles was $2.17 \%$, it was also found that the area occupied by the white pulp in total was $13.38 \%$, for the second spleen it was found that the stroma occupied an area of $14.14 \%$, of which the area occupied by the capsule 
was $7.57 \%$, and that occupied by the trabecula was 6.57 , and the area occupied by the red pulp was $72.87 \%$, and that occupied by the parenchyma was $19.14 \%$, of which the area occupied by the PALS was $5.56 \%$, and that occupied by inactive follicles was $4.37 \%$, while the area occupied by active follicles was $2.42 \%$, and that occupied by total white pulp was by $12.35 \%$. For the third spleen it was found that the area occupied by the stroma was $18.64 \%$, of which the area occupied by the capsule was $8.27 \%$, and that occupied by the trabecula was $10.37 \%$, and the area occupied by the red pulp was $68.27 \%$, and that occupied by the parenchyma was $12.52 \%$, of which the area occupied by the PALS was $3.98 \%$, and that occupied by inactive follicles was $5.28 \%$, while that occupied by active follicles was $3.26 \%$, and the total white pulp occupied an area of $12.52 \%$. For the fourth spleen it was found that the area occupied by the stroma was $23.86 \%$, of which the area occupied by the capsule was $11.57 \%$, and that occupied by the trabecula was $12.29 \%$, and the area occupied by the red pulp was $57.28 \%$, and that occupied by the parenchyma was $18.12 \%$, of which the area occupied by the PALS was $1.18 \%$, and that occupied by inactive follicles was $8.12 \%$, while the area occupied by active follicles was $8.82 \%$, and that occupied by the total white pulp was $18.12 \%$, these data are similar to the results of the researchers $[1,5,8]$.

The splenic artery enters the spleen through the hilum, which branches into trabecular arteries, passing into the pulp arteries, which branch into red pulp. An artery passing through a white pulp is called the central. In the red pulp, the central artery branches out in the form of a brush into the cystic arterioles. At the end of cystic arterioles, there is a thickening - an arterial sheath, clearly expressed in pigs [20].

The PALS perform the function of sphincters that block blood flow, as contractile filaments have been found in the endothelium of ellipsoids or arterioles of the PALS. Short arterial capillaries follow, most of which fall into the venous sinuses. Some arterial capillaries open into the reticular tissue of the red pulp (open bloodstream), and then into the venous capillaries. Blood from the venous capillaries is routed to the trabecular veins and then to the splenic vein according to Pabst and Reilmann [23].

According to Papenfuss and Cesta [24], the number of venous sinuses in the spleen of animals of different species is not the same: for example, many of them in rabbits, dogs, guinea pigs, less in cats, cattle and small cattle. The part of the red pulp between the sinuses is called the splenic strands or pulp. The venous system begins with the venous sinuses. In the areas of sinus transition in the veins, there are similarities between the muscle sphincters, when open, blood flows freely through the sinuses into the veins. On the contrary, the closure (due to the reduction) of the venous sphincter leads to the accumulation of blood in the sinuses. The base of the spleen is the reticular tissue in the form of a sponge filled with parenchyma - white and red pulp as found in our research with silver nitrate impregnation, we have also elucidated almost the same results of other authors [24], also note that the white pulp is constructed from lymphoid tissue collected around the arteries in the form of balls called the spleen lymphatic follicles or spleen body. The number of follicles in different animals is different.

The peri-arterial zone depends on the thymus. It occupies a small area of the follicle near the artery and is formed mainly of $T$ lymphocytes and interdigital cells that adsorb antigens. T cells, which have received information about the state of the microenvironment, migrate to the sinuses of the marginal area through capillaries, as has been described by Vashishtha et al. [32]. The follicle centre reflects the functional state of the follicle and can vary widely with infectious diseases. The reproductive centre is a site independent of the thymus and consists of reticular cells and an accumulation of phagocytes. The mantle zone surrounds the peri-arterial zone, the luminous centre and consists of small, densely localised B lymphocytes and a small number of $\mathrm{T}$ lymphocytes, plasma cells and macrophages. The adjacent cells form, so to speak, a crown stratified by circular reticular fibres.

The marginal or marginal zone is a region of transition between the white and red pulps, consisting mainly of $T$ and $B$ lymphocytes and single macrophages, surrounded by marginal or marginal sinusoidal vessels, the results are similar to the author's data [31]. The red pulp of the spleen is $75-78 \%$ of the mass of the organ, consists of reticular tissue with cellular blood elements that give the red colour to the parenchyma. The red pulp contains many special arterioles, capillaries, venules and venous sinuses according to the author who found the same results [27].

A variety of cellular elements are deposited in the venous sinus cavity. The sections of red pulp between the sinuses are called pulp cords, which contain many lymphocytes, and the development of plasma cells occurs. In the red pulp there are macrophages — sple- 
nocytes, which carry out phagocytosis of destroyed red blood cells. As a result of the breakdown of haemoglobin, bilirubin and iron-containing transferrin are formed and are secreted into the blood. For the histological study of dromedary spleens, the capsule surrounding the organ is very dense thick surrounding the splenic parenchyma, the outermost layer of the splenic capsule was composed of epithelial cells and divided into two layers: outer and inner clearly distinguished, results identical to those of Mollejo et al. [21], Nolte et al. [22], and Eddine Djallal et al. [6].

The outer layer mainly consisted of connective tissue including collagen, rubber bands and fibroblasts and SMC. The inner layer was made up mostly of SMC that appear parallel along the longitudinal cut. Trabeculae extend from the capsule and branch out, so that it divides the area into several parts, are distinguished by the presence of white fibres and smooth muscle fibres. At high magnification, it was observed that the space between the capsule and the parenchyma contained red blood cells, so the surface of the white pulp was large, irregular in shape, the PALS had a clear surface with a branching central artery in several branches, the lymphatic follicles and the marginal zone were very clear. A large marginal area surrounded the white pulp and it was contained in sheathed arteries and SMC. Also, it was observed that the marginal sinus of the marginal zone infiltrates in the marginal zone in the direction of the red pulp supplying the blood directly in the adjacent venous sinuses whose ends which appear open with the marginal zone and penetrate into the reticular mesh of the red pulp and bypass the reticular mesh of the red pulp. It was found that blood from the red pulp collects in the venous sinuses which enter the trabeculae and merge into the trabecular veins, the trabecular veins then converge at the hilum to form the splenic vein which drains to the exterior of the organ, as has been demonstrated by Rahmoun et al. [29].

Regarding the red pulp, it was found to be composed of a mesh of splenic cords and venous sinuses. At high magnification, the splenic cords are composed of reticular fibres, reticular cells and macrophages. Again, under the microscope it was found that the venous sinuses can occupy the entire surface of the red pulp including, they are lined with epithelial tissue and rest on a basement membrane, the periciliary arteries and arteriolar capillaries are also located in red pulp, data similar to research by Gnanadevi et al. [9], Ikpegbu et al. [10] and Jaji et al. [11].

\section{CONCLUSIONS}

Anatomical and topographical study of the spleen in the dromedary from southern Algeria has revealed that it has dens identical to those of ruminants. Histologically, the structure of the spleen of the dromedary has a similar analogy to those of other mammals, the stroma consists of a capsule that envelops the entire organ with trabecular infiltration throughout the parenchyma of the organ, which separates it in a well-defined lobule of red and white pulp. The white pulp of the spleen shows the PALS and lymphoid follicles, the marginal area separates the red pulp from the white could also be clearly demarcated. In the first group, secondary lymphoid follicles occur in new places along the blood vessels. The tissue components of the dromedary spleen are characterized by primary lymphoid follicles, against the background of significant changes corresponding to the quantitative parameters of immunogenesis, primary lymphoid follicles, accompanied respectively by an increase in the relative area of the stroma and the relationship between stromal and parenchymal components of the organ.

\section{Acknowledgements}

The authors wish to thank the team of the histology laboratory of the faculty of veterinary sciences of Taoura, University of Souk-ahras Algeria, for their support and help throughout the research period.

Conflict of interest: None declared

\section{REFERENCES}

1. Almenar S, Rios-Navarro C, Ortega M, et al. Anatomy, immunohistochemistry, and numerical distribution of human splenic microvessels. Ann Anat. 2019; 224: 161-171, doi: 10.1016/j.aanat.2019.05.004, indexed in Pubmed: 31121286.

2. Bar-Ephraïm YE, Mebius RE. Innate lymphoid cells in secondary lymphoid organs. Immunol Rev. 2016; 271(1): 185-199, doi: 10.1111/imr.12407, indexed in Pubmed: 27088915.

3. Dijkstra CD, Veerman A. Normal anatomy, histology, ultrastructure, rat. Hemopoietic System. 1990: 185-193, doi: 10.1007/978-3-642-84110-1_28.

4. Dos Santos BS, Gomes C, Camargo J, et al. Primary splenic torsion associated with accessory spleen in a dog. Acta Scientiae Vet. 2019; 47, doi: 10.22456/1679-9216.97394.

5. Dubey A, Agnihotri D, Jethani SL, et al. Estimation of gestational age using fetal liver morphometry. Nat J Clin Anat. 2018; 7(3): 134, doi: 10.4103/2277-4025.294763.

6. Eddine Djallal R, Amine Mohamed F, Manel H, et al. Morpho-histological study of spleen ontogenesis in lambs during antenatal and posnatal period. J World's Poultry Res. 2020; 10(1): 12-16, doi: 10.36380/scil.2020.ojafr2. 
7. Ernst L. Spleen. Color Atlas of Human Fetal and Neonatal Histology. 2019: 261-268, doi: 10.1007/978-3-030-11425-1_25.

8. Gavrilin PN, Gavrilina EG, Evert VV. Histoarchitectonics of the parenchyma of lymph nodes of mammals with different structure of intranodal lymphatic channel. Ukrainian J Ecol. 2017; 7(3): 96-107, doi: 10.15421/2017 54.

9. Gnanadevi R, Senthilkumar S, Kannan TA, et al. Comparative histoarchitectural study of splenic components in sheep and goat. Int J Curr Microbiol App Sci. 2019; 8(05): 1387-1394, doi: 10.20546/ijcmas.2019.805.158.

10. Ikpegbu I, Ibe CS, Nlebedum UC, et al. The spleen morphology of the african giant pouch rat (Cricetomys Gambianus-Waterhouse, 1840) from Eastern Nigeria. J Animal Husbandry Dairy Sci. 2019; 3(1): 20-25, doi: 10.30954/2277-940x.01.2019.2.

11. Jaji A, Saidu A, Mahre M, et al. Morphology, morphometry and histogenesis of the prenatal dromedary (camelus dromedarius) spleen. Macedonian Vet Rev. 2019; 42(2): 141-149, doi: 10.2478/macvetrev-2019-0018.

12. Johnson CD. Spleen. Mayo Clinic Gastrointestinal Imaging Review. 2014: 753-792, doi: 10.1093/ $\mathrm{med} / 9780199862153.003 .0009$.

13. Kage M, Kondou R, Ogata T. Anatomy of the spleen and pathology of hypersplenism. Clin Invest Portal Hyper. 2019: 25-34, doi: 10.1007/978-981-10-7425-7_3.

14. Kannan TA, Ramesh G, Ushakumary S, et al. Thymic Hassall's corpuscles in Nandanam chicken - light and electronmicroscopic perspective (Gallus domesticus). J Anim Sci Technol. 2015; 57(1): 30, doi: 10.1186/s40781015-0064-2, indexed in Pubmed: 26430516.

15. Kuper $H$, Marmot M, Hemingway $H$. Systematic review of prospective cohort studies of psychosocial factors in the etiology and prognosis of coronary heart disease. Semin Vasc Med. 2002; 2(3): 267-314, doi: 10.1055/s-200235401, indexed in Pubmed: 16222620.

16. Mahadevan V. Anatomy of the pancreas and spleen. Surgery (Oxford). 2016; 34(6): 261-265, doi: 10.1016/j. mpsur.2016.03.014.

17. Masternak MM, Bartke A. Growth hormone, inflammation and aging. Pathobiol Aging Age Relat Dis. 2012; 2, doi: 10.3402/pba.v2i0.17293, indexed in Pubmed: 22953033.

18. Matsuno K, Ezaki T, Kotani M. Splenic outer periarterial lymphoid sheath (PALS): an immunoproliferative microenvironment constituted by antigen-laden marginal metallophils and ED2-positive macrophages in the rat. Cell Tissue Res. 1989; 257(3): 459-470, doi: 10.1007/BF00221456, indexed in Pubmed: 2790931.

19. McGaha TL, Karlsson MC. Apoptotic cell responses in the splenic marginal zone: a paradigm for immunologic reactions to apoptotic antigens with implications for autoimmunity. Immunol Rev. 2016; 269(1): 26-43, doi: 10.1111/imr.12382, indexed in Pubmed: 26683143.

20. Middleton DJ, Westbury HA, Morrissy CJ, et al. Experimental Nipah virus infection in pigs and cats. J Comp Pathol. 2002; 126(2-3): 124-136, doi: 10.1053/jcpa.2001.0532, indexed in Pubmed: 11945001.
21. Mollejo M, Algara P, Mateo MS, et al. Splenic small B cell lymphoma with predominant red pulp involvement: a diffuse variant of splenic marginal zone lymphoma. Histopathology. 2002; 40(1): 22-30, doi: 10.1046/j.13652559.2002.01314.x.

22. Nolte MA, Hamann A, Kraal G, et al. The strict regulation of lymphocyte migration to splenic white pulp does not involve common homing receptors. Immunology. 2002; 106(3): 299-307, doi: 10.1046/j.1365-2567.2002.01443.x, indexed in Pubmed: 12100717.

23. Pabst R, Reilmann H. Regeneration of heterotopically transplanted autologous splenic tissue. Cell Tissue Res. 1980; 209(1): 137-143, doi: 10.1007/BF00219930, indexed in Pubmed: 7428023.

24. Papenfuss T, Cesta M. Spleen. Mol Integ Toxicol. 2017: 37-57, doi: 10.1007/978-3-319-47385-7_2.

25. Paraskevas GK, Koutsouflianiotis KN, Nitsa Z, et al. Knowledge of the anatomy and physiology of the spleen throughout Antiquity and the Early Middle Ages. Anat Sci Int. 2016; 91(1): 43-55, doi: 10.1007/s12565-015-0305-y, indexed in Pubmed: 26507317.

26. Prasad A. Ultrasonographic evaluation of fetal gestational age in different trimesters from various anatomical biometric parameters. Indian J Anat. 2018; 7(6): 590-594, doi: 10.21088/ija.2320.0022.7618.3.

27. Quesada J, Viilena MI, Agulleiro B. Structure of the spleen of the sea bass (Dicentrarchus labrax): A light and electron microscopic study. J Morphol. 1990; 206(3): 273-281, doi: 10.1002/jmor.1052060304, indexed in Pubmed: 29865770.

28. Rahman N, Tandon R, Ghaus F, et al. Comparative anatomy of spleen: histomorphometric study in human, goat, buffalo, rabbit and rat. Acad Anat Int. 2016; 2(1), doi: 10.21276/aanat.2016.2.1.6.

29. Rahmoun DE, Lieshchova MA, Fares MA. Morphological and radiological study of lymph nodes in dromedaries in Algeria. Reg Mech Bios. 2020; 11(2): 330-337, doi: 10.15421/022050.

30. Shringi N. Morphometry of spleen in white Yorkshire pig (Sus scrofa). Int J Pure Applied Biosci. 2017; 5(4): 755-757, doi: 10.18782/2320-7051.5555.

31. Silva-O'Hare J, de Oliveira IS, Klevorn T, et al. Disruption of splenic lymphoid tissue and plasmacytosis in canine visceral leishmaniasis: changes in homing and survival of plasma cells. PLoS One. 2016; 11(5): e0156733, doi: 10.1371/journal.pone.0156733, indexed in Pubmed: 27243459

32. Vashishtha K, Gaur V, Kapoor K, et al. Morphometric study of human foetal spleen: a study from North-India. Int J Anat Res. 2018; 6(4.3): 5983-5988, doi: 10.16965/ ijar.2018.390.

33. Xu M, Li W, Yang S, et al. Morphological characterization of postembryonic development of blood-spleen barrier in duck. Poult Sci. 2020; 99(8): 3823-3830, doi: 10.1016/j.psj.2020.05.012, indexed in Pubmed: 32731968. 